\title{
Correction to: Early Intervention
}

Michael J. Guralnick and Mary Beth Bruder

\section{Correction to:}

Chapter 39 in: J. L. Matson (ed.), Handbook of Intellectual Disabilities, Autism and Child Psychopathology Series, https://doi.org/10.1007/978-3-030-20843-1_39

The original version of Chapter 39 was inadvertently published with the following article note. The article note has been removed from the chapter in the book.

The updated online version of this book can be found at https://doi.org/10.1007/978-3-030-20843-1_39 